\title{
Ventilatory Threshold Detection: A New Method Based on Heart Rate Variability
}

\author{
G Merati ${ }^{1,2}$, S Rampichini ${ }^{1}$, E Cè̀ ${ }^{1}$, M Sangiovanni ${ }^{1}$, \\ P Castiglioni $^{2}$, M Di Rienzo ${ }^{2}$, A Veicsteinas ${ }^{1,2}$ \\ ${ }^{1}$ Institute of Physical Exercise, Health, and Sports, University of Milan, Milan, Italy \\ ${ }^{2}$ Center of Bioengineering, Don C. Gnocchi Foundation, Milan, Italy
}

\begin{abstract}
Ventilatory threshold (VT) is one of the best indexes of aerobic fitness, but its evaluation is laborious and expensive. The High Frequency $(H F)$ component of the heart-rate spectrum is influenced by ventilation: thus, changes in the HF component during exercise might reflect the ventilatory adaptations occurring at VT. Eleven subjects with different aerobic fitness levels were enrolled. RR time series were recorded during an incremental ergometric exercise. $V T_{2}$ (uncompensated ventilatory threshold) was identified by averaging the values from 2 traditional methods based on gas analysis and visual inspection of the ventilatory curve, and from the detection of a deflection point in respiratory sinus arrhythmia from the $R-R$ interval spectrum. The agreement between the two methods of VT detection was high (mean percentage error $=5 \%$ ). Our results may provide a new simple and inexpensive method to detect VT during an exercise test based on heart rate data.
\end{abstract}

\section{Introduction}

Ventilatory threshold (VT) is currently considered one of the best indexes of aerobic fitness, especially in endurance performance evaluations and cardiac rehabilitation [1,2]. However, its measure requires the continuous recording of pulmonary ventilation, which is difficult outside the clinical setting and needs expensive instruments. Indeed, ventilatory and gas exchange data has to be recorded on a breath-by-breath basis to produce reliable estimates of VT [3].

Conversely, during an incremental exercise test heart rate (HR) can be easily recorded on a beat-to-beat basis (i.e. as RR interval series) by inexpensive methods, which can be simply applied to different clinical settings and to on-field evaluations. In these last 20 years the analysis of heart rate variability (HRV) provided new tools to examine HR adaptation and neural autonomic control in different clinical diseases [4,5], experimental conditions
[6,7] and environments [8]. In particular, as it is well known that respiratory activity modulates HR [9], the High Frequency (HF) component of HR spectra (conventionally ranging from 0.150 to $0.400 \mathrm{~Hz}$ ) is widely used to assess the presence and the magnitude of the respiratory sinus arrhythmia [10]. Recently, the modification in HRV during steady state exercise below and above VT has been demonstrated [11]. The changes in HF during exercise might thus reflect the ventilatory adaptations occurring at VT. Aim of this study was to assess a new approach to detect VT during an ergometric test, by means of spectral analysis of HR data.

\section{Methods}

\subsection{Subjects}

Eleven subjects (7 males, 4 females; age 26.1 $\pm 3.0 \mathrm{yrs}$; weight $66.3 \pm 11.8 \mathrm{~kg}$; high $172 \pm 7 \mathrm{~cm}$; all no-smokers) with different aerobic fitness levels $\left(\mathrm{VO}_{2}\right.$ peak ranging from 31 to $60 \mathrm{ml} / \mathrm{kg} / \mathrm{min}$ ) were enrolled.

Table 1. Individual characteristics of the enrolled subjects.

\begin{tabular}{cccccc}
\hline Sbj. & $\begin{array}{c}\text { Gender } \\
(\mathrm{M} / \mathrm{F})\end{array}$ & $\begin{array}{c}\text { Weight } \\
(\mathrm{kg})\end{array}$ & $\begin{array}{c}\text { Height } \\
(\mathrm{cm})\end{array}$ & $\begin{array}{c}\text { Age } \\
(\mathrm{yrs})\end{array}$ & $\begin{array}{c}\mathrm{VO}_{2} \text { peak } \\
(\mathrm{ml} / \mathrm{min})\end{array}$ \\
\hline 1 & $\mathrm{M}$ & 63 & 177 & 22 & 3665 \\
2 & $\mathrm{M}$ & 66 & 175 & 27 & 3150 \\
3 & $\mathrm{~F}$ & 55 & 174 & 22 & 1848 \\
4 & $\mathrm{M}$ & 83 & 183 & 28 & 3457 \\
5 & $\mathrm{M}$ & 79 & 172 & 25 & 3484 \\
6 & $\mathrm{M}$ & 84 & 179 & 31 & 3576 \\
7 & $\mathrm{M}$ & 63 & 169 & 22 & 2711 \\
8 & $\mathrm{~F}$ & 60 & 170 & 29 & 3140 \\
9 & $\mathrm{~F}$ & 52 & 158 & 28 & 1615 \\
10 & $\mathrm{~F}$ & 52 & 161 & 27 & 2170 \\
11 & $\mathrm{M}$ & 72 & 170 & 26 & 2399 \\
\hline
\end{tabular}


The individual anthropometric and aerobic fitness levels values are shown in Table 1. Each subject signed an informed consent and underwent a preliminary physical examination and a 12-lead standard ECG: none of them showed any sign of cardiorespiratory disease.

\subsection{Experimental procedures}

After a 5 min warm up without load each subject performed an incremental exercise on an electronically braked bicycle ergometer (Monark 839 C, Sweden). The ramp protocol consisted in increments of $25 \mathrm{~W} / \mathrm{min}$, starting from $50 \mathrm{~W}$, until volitional exhaustion (constant pedalling frequency $=60 \mathrm{rpm}$ ).

HR was recorded on a beat-to-beat basis by a HR monitor (S810, Polar, Finland) during the incremental test and for 10 minute of recovery.

Breath-by-breath measurements of $\mathrm{O}_{2}$ uptake $\left(\mathrm{VO}_{2}\right)$, carbon dioxide production $\left(\mathrm{VCO}_{2}\right)$, respiratory frequency (RF) and tidal volume (TV) were performed during the whole test, by means of an automated pre-calibrated gas analyser equipped with a turbine spirometer $\left(\mathrm{K}_{4} \mathrm{~b}^{2}\right.$, Cosmed, Italy).

\subsection{Calculation}

Ventilatory Threshold. Beaver et al. [12] defined $\mathrm{VT}_{2}$ as the work rate associated with the second nonlinear increase of VE (Figure 1, panel a). According to Wasserman et al. [13] $\mathrm{VT}_{2}$ corresponds also to the minimal work rate at which the increase in $\mathrm{VE} / \mathrm{VO}_{2}$ was accompanied by a parallel increase of $\mathrm{VE} / \mathrm{VCO}_{2}$ (Figure 1 , panel b). According to the criteria outlined above, one independent investigator reviewed the plots of each index and made individual determinations of $\mathrm{VT}_{2}$ by combining the two detection methods, in order to improve the accuracy of $\mathrm{VT}_{2}$ determination $\left(\mathrm{VT}_{2}\right.$ Vent/gas in Figure $1)$.

Heart Rate Variability. Each HR recording was preliminarily checked and edited for the presence of artefacts, and then resampled at $20 \mathrm{~Hz}$ and band pass filtered $(0.02-0.05 \mathrm{~Hz})$. The spectral analysis was performed by applying to the filtered signal a running Hann window of $50 \mathrm{~s}$, with a shift of $4 \mathrm{~s}(95 \%$ overlapping). In each window the power spectrum was estimated by the FFT technique and integrated over frequency bands defined as Low Frequency (LF: 0.05$0.15 \mathrm{~Hz})$ and High Frequency $(0.20-1.5 \mathrm{~Hz})$ (Figure 1, panel c).

The respiratory frequency $\left(\mathrm{RF}_{\mathrm{RR}}\right)$ was estimated in each segment as the highest spectral peak in the HF sub-band.

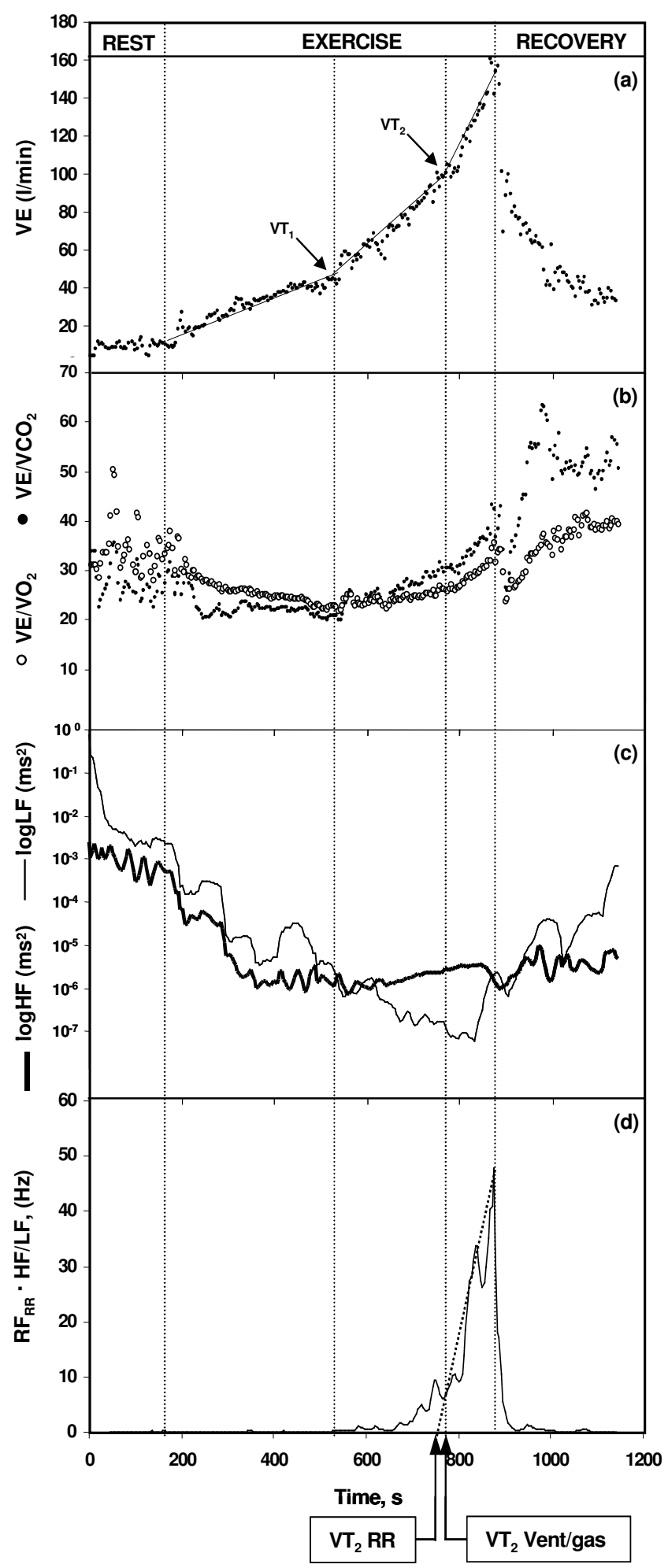

Figure 1. VE, VE/VO2, VE/VCO2, LF, HF, and $\mathrm{RF} * \mathrm{HF} / \mathrm{LF}$ in a representative subject. 
To estimate the effect of the increase in tidal volume during exercise on RR spectra we calculated the ratio between HF and LF (HF/LF). In this way it is possible to "subtract" from the descending trend of $\log (\mathrm{HF})$ the vegetative component estimated by $\log (\mathrm{LF})$, so that the remaining $\mathrm{HF}$ power may be more dependent from the respiratory mechanics. Finally, in order to determine an index which estimate VE changes (where VE=RF*TV) from $\mathrm{HR}$ spectra, we computed the product: $\mathrm{RF}_{\mathrm{RR}}{ }^{*} \mathrm{HF} / \mathrm{LF}$ (Figure 1, panel d). The HF increase corresponding to $\mathrm{VT}_{2}$ was calculated by transforming the area under the $\mathrm{RF}_{\mathrm{RR}}{ }^{*} \mathrm{HF} / \mathrm{LF}$ curve between 0 and the HF/LF peak in a rectangular triangle, from which the position of the left base vertex was localized on the time axis.

\subsection{Statistical analysis}

If not otherwise stated, data are expressed as mean \pm standard deviation. Linear regression was assessed by means of the least squared method. The level of statistical significance was set at $\mathrm{p}<0.05$.

\section{Results}

All the incremental tests were stopped due to subject exhaustion, at a maximal power output ranging from 175 to $325 \mathrm{~W}$. Peak $\mathrm{VO}_{2}\left(\mathrm{VO}_{2} \mathrm{p}\right)$ was showed for each subject in Table 1. The mean of the $\mathrm{VT}_{2}$ values $\left(\mathrm{VT}_{2} \mathrm{GAS}\right.$ ), calculated with the two methods described above, is reported in Table 2 .

Table 2. Mean of $\mathrm{VT}_{2}$ values calculated by two methods.

\begin{tabular}{cccc}
\hline Sbj. & $\begin{array}{c}\mathrm{VT}_{2} \text { from }{\mathrm{VE} / \mathrm{VO}_{2}-}^{-} \\
{\mathrm{VE} / \mathrm{VCO}_{2}}^{\left(\mathrm{mlO}_{2} / \mathrm{min}\right)}\end{array}$ & $\begin{array}{c}\mathrm{VT}_{2} \text { from } \mathrm{VE} \text { (Visual } \\
\text { Inspection Method) } \\
\left(\mathrm{mlO}_{2} / \mathrm{min}\right)\end{array}$ & $\begin{array}{c}\text { Mean } \\
\mathrm{VT}_{2 \text { gas }}\end{array}$ \\
\hline 1 & 3368 & 3273 & 3320 \\
2 & 2828 & 2494 & 2661 \\
3 & 1838 & 1838 & 1838 \\
4 & 2982 & 2489 & 2735 \\
5 & 2806 & 2119 & 2462 \\
6 & 3201 & 2543 & 2298 \\
7 & 2325 & 3040 & 2682 \\
8 & 2931 & 2437 & 2684 \\
9 & 1570 & 1345 & 1457 \\
10 & 1704 & 1912 & 1807 \\
11 & 2066 & 1911 & 1989 \\
\hline
\end{tabular}

The agreement between $\mathrm{VT}_{2}$ values calculated by HRV
$\left(\mathrm{VT}_{2 \mathrm{RR}}\right)$ and breath-by-breath gas analysis $\left(\mathrm{VT}_{2} \mathrm{GAS}\right)$ is shown in Figure 2. The overall error between the two methods was $5 \%$, corresponding to a mean difference in $\mathrm{VT}_{2}$ of $105 \mathrm{ml} / \mathrm{min}$.

\section{Discussion and conclusions}

VT detection by $H R V$. The major finding of this work is the synchronous occurrence of $\mathrm{VT}_{2}$ and the emergence of an HF increase in the normalized spectrogram of HR during an incremental exercise. Such occurrence may therefore be useful to set a new simple method for $\mathrm{VT}_{2}$ detection, based on HRV. This method is simpler than the current methods based on gas exchanges and does not need accurate measurements of minute ventilation: thus, it can be applicable in a wider variety of settings.

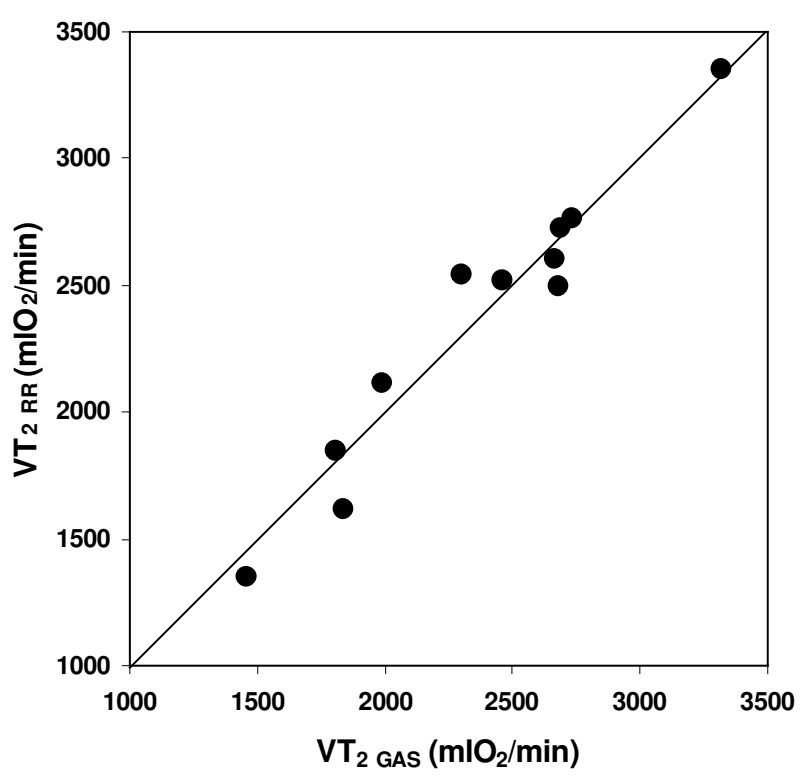

Figure 2. Agreement between $\mathrm{VT}_{2}$ values calculated by HRV $\left(\mathrm{VT}_{2} \mathrm{RR}\right)$ and breath-by-breath gas analysis $\left(\mathrm{VT}_{2 \mathrm{GAS}}\right)$.

In addition, with respect to traditional methods, it reduces the discomfort to the patient due to the need of mouthpieces or facial masks for gas collection. Finally, the presence of an increase in HF values seemed to be independent from the fitness level of the subjects. Thus, such method may be a reliable option in the determination of $\mathrm{VT}_{2}$ in variably fitted individuals. Since vagal modulation is expected to be completely blunted during a heavy exercise (e.g. in the region of anaerobic threshold), it can be speculated that the observed increment in normalized HF power corresponding to VT occurrence may be due to a mechanical effect of breathing on the 
sinus node, as suggested by Cottin et al. [11]. Indeed, a similar effect has been documented in cardiac transplanted patient, in which the complete heart denervation does not eliminate the respiratory sinus arrhythmia [14]. Our data also suggest that the mechanical effect of breathing on respiratory sinus arrhythmia may also depend on the changes in TV which increases with ventilation during an incremental exercise, confirming previous data about the relationship between respiratory sinus arrhythmia amplitude and ventilatory volume [9]. The protocol used in this study does not allow to understand whether the sinus node responds to mechanical stimulations as a real stress receptor (by sensing the increased venous return during inspiration, which dilates the right atrium), or there is a reflex mechanism based on the activation of lung or chest wall receptors [15], or whether this effect can be mediated by metabolic changes (e.g. a direct effects on the sinus node of arterial $\mathrm{pO}_{2}$ and $\mathrm{pCO}_{2}$ changes, as suggested by Perlini et al. [16] in an animal model).

Finally, the simultaneous presence of more than one HF peak in the region of ventilatory threshold is difficult to explain in this experimental setting: it can be due to the interference of pedalling frequency $(1 \mathrm{~Hz})$ on heart rate and/or to the variability of ventilatory pattern in each individual. However, this point needs further investigation.

In conclusion, our results provide a new simple and inexpensive approach to detect $\mathrm{VT}_{2}$ during an incremental exercise test based on beat-to-beat heart rate data.

\section{References}

[1] Digenio AG, Noakes TD, Cantor A, Groeneveld H, Daly L, Mavunda D and Esser JD. Predictors of exercise capacity and adaptability to training in patients with coronary artery disease. J Cardiopulm Rehabil 1997,17:110-120

[2] Reybrouck T, Ghesquiere J, Weymans M and Amery A. Ventilatory threshold measurement to evaluate maximal endurance performance. Int J Sports Med 1986,7:26-29

[3] Svedahl K and MacIntosh BR. Anaerobic threshold: the concept and methods of measurement. Can J Appl Physiol 2003,28:299-323

[4] La Rovere MT, Bigger JT, Jr., Marcus FI, Mortara A and Schwartz PJ. Baroreflex sensitivity and heart-rate variability in prediction of total cardiac mortality after myocardial infarction. ATRAMI Investigators. Lancet 1998,351:478-484

[5] Lombardi F and Mortara A. Heart rate variability and cardiac failure. Heart 1998,80:213-214

[6] Di Rienzo M, Parati G, Castiglioni P, Omboni S, Ferrari AU, Ramirez AJ, Pedotti A and Mancia G.
Role of sinoaortic afferents in modulating BP and pulse-interval spectral characteristics in unanesthetized cats. Am J Physiol 1991,261:H1811H1818

[7] La Rovere MT, Mortara A, Sandrone G and Lombardi F. Autonomic nervous system adaptations to short-term exercise training. Chest 1992,101: 299S-303S

[8] Farrace S, Ferrara M, De Angelis C, Trezza R, Cenni $\mathrm{P}$, Peri A, Casagrande $\mathrm{M}$ and De Gennaro L. Reduced sympathetic outflow and adrenal secretory activity during a 40-day stay in the Antarctic. Int J Psychophysiol 2003,49:17-27

[9] Hirsch JA and Bishop B. Respiratory sinus arrhythmia in humans: how breathing pattern modulates heart rate. Am J Physiol 1981,241:H620H629

[10] Taha BH, Simon PM, Dempsey JA, Skatrud JB and Iber C. Respiratory sinus arrhythmia in humans: an obligatory role for vagal feedback from the lungs. J Appl Physiol 1995,78:638-645

[11] Cottin F, Medigue C, Lepretre PM, Papelier Y, Koralsztein JP and Billat V. Heart rate variability during exercise performed below and above ventilatory threshold. Med Sci Sports Exerc 2004,36:594-600

[12] Beaver WL, Wasserman K and Whipp BJ. A new method for detecting anaerobic threshold by gas exchange. J Appl Physiol 1986,60:2020-2027

[13] Wassermann K, McIlroy MB. Detecting the threshold of anaerobic metabolism in cardiac patients during exercise. Am J Cardiol 1964,14:844-852

[14] Radaelli A, Valle F, Falcone C, Calciati A, Leuzzi S, Martinelli L, Goggi C, Vigano M, Finardi G and Bernardi L. Determinants of heart rate variability in heart transplanted subjects during physical exercise. Eur Heart J 1996,17:462-471

[15] Khayat RN, Przybylowski T, Meyer KC, Skatrud JB and Morgan BJ. Role of Sensory Input from the Lungs in Control of Muscle Sympathetic Nerve Activity During and After Apnea in Humans. J Appl Physiol 2004,97(2):635-40

[16] Perlini S, Solda PL, Piepoli M, Sala-Gallini G, Calciati A, Finardi G and Bernardi L. Determinants of respiratory sinus arrhythmia in the vagotomized rabbit. Am J Physiol 1995,269:H909-H915

Address for correspondence

Giampiero Merati, MD.

Institute of Physical Exercise, Health and Sports (IEFSAS), Faculty of Exercise Science, University of Milan,

Via Colombo 71, 20132 - Milan, Italy.

E-mail address: giampiero.merati@unimi.it 